Gut, 1983, 24, 300-305

\title{
Faecal free fatty acids in tropical sprue and their possible role in the production of diarrhoea by inhibition of ATPases
}

\author{
C TIRUPPATHI, K A BALASUBRAMANIAN, P G HILL, AND V I MATHAN
}

From the Wellcome Research Unit, Christian Medical College Hospital, Vellore, India

SUMmARY Faecal excretion of fatty acids is increased in patients with tropical sprue because of unabsorbed dietary fatty acids. The excretion of fatty acids correlates well with faecal wet weight. In vitro unsaturated fatty acids inhibited Na K-ATPase and Mg-ATPase isolated from basolateral membranes of enterocytes and colonocytes. These findings are a possible explanation for the observed abnormalities in water and electrolyte absorption by the colon in patients with tropical sprue and steatorrhoea.

Colonic water and electrolyte absorption is defective in patients with tropical sprue. ' Faecal free fatty acids could play a role in the pathogenesis of this functional defect of the colon in patients with tropical sprue and steatorrhoea. The precise role of fatty acids in the genesis of diarrhoea associated with steatorrhoea is not clear ${ }^{2}$ but it has been suggested that hydroxy fatty acids could produce a secretory diarrhoea. ${ }^{3-5}$ This paper reports the results of the analysis of faecal fatty acids in a group of patients with tropical sprue and appropriate controls. To investigate the possible role of fatty acids in producing colonic water malabsorption. their effect on $\mathrm{Mg}^{++}$and $\mathrm{Na}^{+} \mathrm{K}^{+}$adenosine triphosphatase (Mg-ATPase and $\mathrm{Na}$ K-ATPase) isolated from the basolateral membranes of enterocytes and colonocytes were investigated in vitro.

\section{Methods}

\section{PATIENTS}

CLINICAL STUDY

Eighteen patients with tropical sprue (all with steatorrhoea and defective xylose absorption) admitted consecutively to a metabolic ward from rural North Arcot District, Tamil Nadu, and 12 age, sex, matched controls without malabsorption were studied. Intestinal function was tested as previously described. ${ }^{6}$ The patients and controls were on the

Correspondence and reprint requests: Professor V I Mathan. Welleome Research Unit. CMC Hospital. Vellore 6.320(14. India.

Received for publication $1+$ June 1982 ward diet containing $50 \mathrm{~g}$ fat per day and the analysis was done after at least one week on this diet. The dietary fat was mainly groundnut oil and analysis of a typical 24 hour diet showed that palmitic (16:0), oleic (18:1), and linoleic (18:2) acids were the major fatty acids (Fig. 1).

Faeces were passed into polyethylene containers and kept immediately by the patients in a freezer $\left(-2()^{\circ} \mathrm{C}\right)$. The samples obtained during 72 hours were mixed and homogenised while still cold.

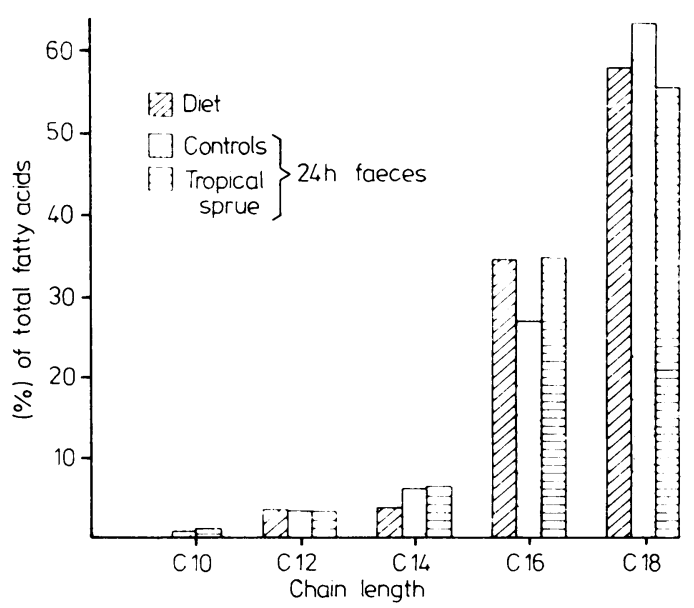

Fig. 1 Comparison of dietary fatty acids with faecal fatty. acids in control subjects and patients with tropical sprue. C10 to C18 fatty acids only were taken for calculating 100); distribution. 
Aliquots of homogenate were quantitatively analysed for total fatty acids ${ }^{7}$ and for total free fatty acids. ${ }^{x}$ Aliquots of a toluene extract were dried and free fatty acids methylated and extracted as described by Morrison and Smith." Hydroxy fatty acids were separated as described, ${ }^{10}$ except that the liquid phase. SE-30, was used at 3\% on GASCHROM Q80-100 (Applied Science Labs, Pa, USA) using a Pye 104 gas chromatograph. For other fatty acids, the method of Matthys, Christophe, and Verdonk "I was followed under isothermal conditions. The percentage distribution of each fatty acid was determined by the peak height and retention time method. ${ }^{12}$ Fatty acids were identified by the use of pure standards obtained from Sigma Chemical Co., USA.

\section{IN VITRO STUDIES}

White rats weighing $150-200 \mathrm{~g}$ were killed by a blow on the head, the intestines removed and washed with ice cold saline and mucosa scraped from small intestine and colon separately. All procedures were carried out at $4^{\circ} \mathrm{C}$ unless otherwise specified.

Small intestinal enterocyte basolateral membrane was prepared essentially as described by Quigley and Gotterer. ${ }^{13}$ Briefly, a $5 \%$ homogenate in $5 \mathrm{mM}$ EDTA, pH 7.4, prepared in a Sorvall omnimixer at a speed of 140 for 25 seconds, was filtered through nylon mesh and centrifuged at $700 \mathrm{~g}$ for 10 minutes. The supernatant was further centrifuged at $10000 \mathrm{~g}$ for 10 minutes and the mitochondrial pellet obtained was processed after ageing and separation on a sucrose density gradient. Final preparations of basolateral membrane was suspended in $10 \mathrm{mM}$ Tris, $2.5 \mathrm{mM}$ EDTA, $0.25 \mathrm{mM}$ sucrose, $\mathrm{pH} 7.2$, with the protein concentration adjusted to 1.5 to 2.5 $\mathrm{mg} / \mathrm{ml}$, and stored at $-20^{\circ} \mathrm{C}$ till further use. $\mathrm{Na}$ K-ATPase was enriched 20-30 fold over original homogenate in this preparation.

Experiments showed that without minor modification, the recovery of $\mathrm{Na} \mathrm{K}$-ATPase from the colonic mucosa after the Quigley and Gotterer ${ }^{13}$ procedure was low. The initial homogenising buffer, therefore, was modified as follows: $0 \cdot 25 \mathrm{M}$ sucrose, $30 \mathrm{mM}$ L-histidine, $2.0 \mathrm{mM}$ EDTA, $\mathrm{pH}$ of 7.0 adjusted with Tris. For homogenisation the Sorvall omnimixer was set at a speed of 180 and the homogenisation done for 60 seconds. Subsequent steps for purification were identical with the small intestinal scrapings. $\mathrm{Na}$ K-ATPase was enriched 10-12 fold by this method in the basolateral membrane preparation from colonocytes. Proteins were determined by the method of Lowry et al. ${ }^{14}$

ATPase was assayed as described by Quigley and Gotterer $^{13}$ with slight modifications. The assay medium consisted of $60 \mathrm{mM}$ Tris imidazole buffer, $\mathrm{pH} 7 \cdot 0,6 \mathrm{mM}$ ATP (di-sodium salt grade II, Sigma, $\mathrm{pH}$ adjusted to 7.0 with Tris), $10 \mathrm{mM} \mathrm{MgCl}_{2}, 120$ $\mathrm{mM} \mathrm{NaCl}$, and $20 \mathrm{mM} \mathrm{KCl}$. Basolateral membrane ( $50 \mu \mathrm{g}$ protein) was added to give the final volume of $1.5 \mathrm{ml}$. The reaction was started either by the addition of the enzyme or by the addition of ATP and magnesium chloride together. Incubation was at $37^{\circ} \mathrm{C}$ for 20 minutes in a shaking water bath and the reaction was stopped by the addition of $0.5 \mathrm{ml}$ of $46 \%$ TCA. Inorganic phosphate released was measured by the method of Taussky and Shorr. ${ }^{15}$

ATPase activity was measured under three conditions: in the presence of $\mathrm{Mg}^{2+}, \mathrm{Na}^{+}$, and $\mathrm{K}^{+}$ (total ATPase), in the presence of $\mathrm{Mg}^{2+}$ and $\mathrm{Na}^{+}$ (Mg-ATPase), and in the presence of $\mathrm{Mg}^{2+}, \mathrm{Na}^{+}$, $\mathrm{K}^{+}$, and $1 \mathrm{mM}$ ouabain (ouabain insensitive ATPase). The Na K-ATPase was calculated by subtracting the appropriate values from the total ATPase activity. Fatty acid inhibition studies were carried out by adding fatty acids as solutions of 100 times the final concentration in $90 \%$ ethanol. ${ }^{16}$ In all such assays, controls contained the same level of ethanol without fatty acids.

\section{Results}

FAECAL FATTY ACIDS IN TROPICAL SPRUE

The mean total fatty acids in the faeces of controls was $3.5 \mathrm{~g} / 24 \mathrm{~h}$ (SEM 0.09 ) and $92 \%$ of these were free fatty acids $(3.2 \mathrm{~g})$. In contrast, in patients with tropical sprue the total fatty acids were increased $(11 \cdot 1 \mathrm{~g} / 24 \mathrm{~h}$, SEM $0 \cdot 3)$ and free fatty acids while only $77.5 \%$ of total were more $(8.6 \mathrm{~g} / 24 \mathrm{~h})$ than in controls. Palmitic (16:0), stearic (18:0), and oleic (18:1) acids were the predominant faecal fatty acids in both groups (Table 1). Unsaturated fatty acids

Table 1 Amounts of individual stool free fatty acids in control and tropical sprue patients

\begin{tabular}{|c|c|c|c|c|c|c|c|c|c|c|c|c|}
\hline & $n$ & & $12: 0$ & $14: 0$ & $16: 0$ & $18: 0$ & $18: 0^{*}$ & $20: 0$ & $22: 0$ & $18: 1$ & $18: 2$ & $20: 4$ \\
\hline Controls & 12 & $\begin{array}{l}\mathrm{g} / 24 \mathrm{~h} \\
\text { SEM }\end{array}$ & $\begin{array}{c}0.19 \\
(0 \cdot 02)\end{array}$ & $\begin{array}{l}0 \cdot 23 \\
(0 \cdot 01)\end{array}$ & $\begin{array}{l}0.84 \\
(0.03)\end{array}$ & $\begin{array}{l}0 \cdot 82 \\
(0 \cdot 03)\end{array}$ & $\begin{array}{l}0.09 \\
(0.01)\end{array}$ & $\begin{array}{l}0.05 \\
(0 \cdot 003)\end{array}$ & $\begin{array}{l}0 \cdot 14 \\
(0 \cdot 008)\end{array}$ & $\begin{array}{l}0.53 \\
(0.02)\end{array}$ & $\begin{array}{c}0.14 \\
(0.01)\end{array}$ & $\begin{array}{c}0 \cdot 12 \\
(0 \cdot 01)\end{array}$ \\
\hline Tropical sprue & 18 & $\begin{array}{l}\mathrm{g} / 24 \mathrm{~h} \\
\text { SEM }\end{array}$ & $\begin{array}{c}0.28 \\
(0.01)\end{array}$ & $\begin{array}{c}0.43 \\
(0.01)\end{array}$ & $\begin{array}{l}2.65 \\
(0 \cdot 08)\end{array}$ & $\begin{array}{l}2 \cdot 62 \\
(0 \cdot 10)\end{array}$ & $\begin{array}{l}0.13 \\
(0.01)\end{array}$ & $\begin{array}{l}0.23 \\
(0 \cdot 007)\end{array}$ & $\begin{array}{c}0 \cdot 31 \\
(0 \cdot 01)\end{array}$ & $\begin{array}{c}1.37 \\
(0.06)\end{array}$ & $\begin{array}{c}0.32 \\
(0.01)\end{array}$ & $\begin{array}{c}0 \cdot 15 \\
(0 \cdot 01)\end{array}$ \\
\hline
\end{tabular}

\footnotetext{
* Hydroxystearic acid
} 
amounted to $25 \% \mathrm{c}$ and $21 \% \mathrm{c}$ of the total fatty acids in the controls and patients with tropical sprue respectively. Arachidonic acid (20:4), which is virtually absent from the south Indian diet, was present in similar amounts in both groups and may represent the loss of endogenous fat. The major dietary fatty acids are in the $\mathrm{Cl}(0-\mathrm{C} 18$ series. The similarity of the fatty acids profile in diet and faeces suggests that in controls and in patients with tropical sprue most of the faecal fat is of dietary, rather than endogenous, origin (Fig. 1).

Hydroxystearic acid was present in measurable amounts in eight of 12 controls and in seven of 18 patients with tropical sprue. The largest amount of hydroxystearic acid was $1.0 \mathrm{~g} / 24 \mathrm{~h}$ in a tropical sprue patient with a 24 hour stool weight of $869 \mathrm{~g}$. Hydroxystearic acid excretion varied from $0.02-$ $1.0 \mathrm{~g} / 24 \mathrm{~h}$ and stool weight from $151-869 \mathrm{~g} / 24 \mathrm{~h}$ in the 15 subjects in whom hydroxystearic acid could be detected. Stool weight for the 18 patients with tropical sprue ranged from $130-1244 \mathrm{~g} / 24 \mathrm{~h}$. There was no significant correlation between stool weight and excretion of hydroxy fatty acids in the 30 subjects included in the study. The three day mean stool wet weight showed a highly significant correlation with total stool fat $(r=0.73)$ and with unsaturated fatty acid excretion ( $r=0 \cdot 74)$ (Fig. 2). A significant correlation between total stool fat and unsaturated fatty acids was also observed $(r=0 \cdot 85)$.

EFFECT OF FATTY ACID ON ATPASES in vitro

Inhibition of basolateral membrane $\mathrm{Na} \mathrm{K}$-ATPase by unsaturated fatty acids $(0.05 \mathrm{mM})$ ranged from $50.5 \%$ (oleic) to $69.5 \%$ (arachidonic) for the small intestinal and $43.9 \%$ (oleic) to $75.2 \%$ (linoleic) for

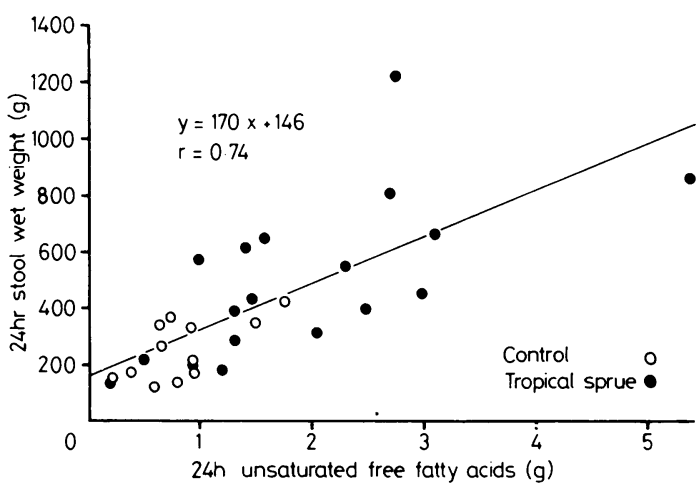

Fig. 2 Correlation of stool wet weight and faecal excretion of unsaturated free fatty acids in control subjects and patients with tropical sprue.

the large intestinal preparations. Saturated fatty acids, hydroxy fatty acids, and methylester of oleic acid produced considerably lower inhibition. The inhibition by various fatty acids of Mg-ATPase was similar to that for Na K-ATPase except that the percentage inhibition was in general less (Table 2).

The $\mathrm{Km}$ for ATP for the colonocyte $\mathrm{Na} \mathrm{K}$ ATPase was higher than that of the enterocyte enzyme. The colonic $\mathrm{Na} \mathrm{K}-\mathrm{ATPase} \mathrm{Km}$ was altered in the presence of $0 \cdot 16$ molar ethanol, but no such alteration occurred for the enterocyte enzyme. Similarly, the $\mathrm{Ki}$ for oleic acid was higher for the colonocyte enzyme. The $\mathrm{pH}$ optimum and optimum concentration of $\mathrm{Na}^{+}$and $\mathrm{K}^{+}$were identical for the two enzymes (Table 3).

$\mathrm{Na}$ K-ATPase from the colon or the small

Table 2 Percentage inhibition of rat small intestinal and colonic ATPases by different fatty acids at 0.05 mM concentration

\begin{tabular}{|c|c|c|c|c|c|}
\hline \multirow[b]{3}{*}{ Fatty acids } & \multirow[b]{3}{*}{ Chain length } & \multicolumn{4}{|c|}{ Percentage inhibition } \\
\hline & & \multicolumn{2}{|c|}{ Na K-ATPase } & \multicolumn{2}{|c|}{ Mg-ATPase } \\
\hline & & $\begin{array}{l}\text { Simall } \\
\text { intestine }\end{array}$ & Colon & $\begin{array}{l}\text { Small } \\
\text { intestine }\end{array}$ & Colon \\
\hline Octanoic & $8: 0$ & $5 \cdot 5 \pm 1 \cdot 2$ & $0 \cdot 0$ & $9 \cdot 5 \pm 2 \cdot 8$ & $0 \cdot 0$ \\
\hline Lauric & $12: 0$ & $12 \cdot 2 \pm 1 \cdot 4$ & $0 \cdot 0$ & $10 \cdot 6 \pm 2 \cdot 2$ & $0 \cdot 0$ \\
\hline Myristic & $14: 0$ & $32 \cdot 2 \pm 0 \cdot 6$ & $21 \cdot 4 \pm 1 \cdot 0$ & $23 \cdot 1 \pm 1 \cdot 6$ & $5 \cdot 0 \pm 0 \cdot 1$ \\
\hline Palmitic & $16: 0$ & $21 \cdot 2 \pm 1 \cdot 0$ & $3 \cdot 0 \pm 1 \cdot()$ & $0 \cdot 0$ & $11 \cdot 2 \pm 0 \cdot 4$ \\
\hline Stearic & $18: 0$ & $11 \cdot 8 \pm 0.5$ & $6 \cdot 1 \pm 0 \cdot 3$ & $0 \cdot 0$ & $14 \cdot 8 \pm 0 \cdot 5$ \\
\hline Arachidic & $20: 0$ & $9 \cdot 6 \pm 1 \cdot 0$ & $32 \cdot 2 \pm 0 \cdot 7$ & $3.9 \pm 0.5$ & $26 \cdot 7 \pm 0 \cdot 9$ \\
\hline Oleic & $18: 1$ & $50 \cdot 5 \pm 1 \cdot 0$ & $43 \cdot 9 \pm 0 \cdot 4$ & $33 \cdot 5 \pm 1 \cdot 5$ & $40 \cdot 3 \pm 0 \cdot 6$ \\
\hline Methyl oleate & $18: 1$ & $17 \cdot 2 \pm 1 \cdot 0$ & $*$ & $11 \cdot 7 \pm 0 \cdot 6$ & $*$ \\
\hline Linoleic & $18: 2$ & $68 \cdot 2 \pm 1 \cdot 0$ & $75 \cdot 2 \pm 0 \cdot 3$ & $51 \cdot 6 \pm 0 \cdot 8$ & $50 \cdot 9 \pm 0 \cdot 3$ \\
\hline Linolenic & $18: 3$ & $56 \cdot 7 \pm 1 \cdot 1$ & $58 \cdot 3 \pm 0 \cdot 4$ & $41 \cdot 8 \pm 1 \cdot 2$ & $41 \cdot 9 \pm 0 \cdot 0$ \\
\hline Arachidonic & $20: 4$ & $69 \cdot 5 \pm 0 \cdot 9$ & $68 \cdot 5 \pm 0 \cdot 7$ & $69 \cdot 7 \pm 1 \cdot 8$ & $53 \cdot 3 \pm 0 \cdot 2$ \\
\hline Ricinoleic & $18: 1-\mathrm{OH}$ & $33 \cdot 5 \pm 0 \cdot 9$ & $37 \cdot 3 \pm 1 \cdot 0$ & $13 \cdot 3 \pm 1 \cdot 8$ & $10 \cdot 3 \pm 0 \cdot 4$ \\
\hline 12-Hydroxystearic & $18: 0-\mathrm{OH}$ & $18 \cdot 8 \pm 0 \cdot 6$ & $10 \cdot 0 \pm 0 \cdot 7$ & $28 \cdot 5 \pm 2 \cdot 4$ & $12 \cdot 5 \pm 0 \cdot 3$ \\
\hline
\end{tabular}

${ }^{*}$ Not tested. The results are expressed as mean and SEM for three determinations with duplicates. 
Table 3 Comparison of properties of enterocyte and colonocyte Na K-ATPase

\begin{tabular}{|c|c|c|}
\hline & \multicolumn{2}{|c|}{ Na K-ATPase } \\
\hline & $\begin{array}{l}\text { Small } \\
\text { intestine }\end{array}$ & Colon \\
\hline Km for ATP & $9 \times 10^{-4} \mathrm{M}$ & $16 \times 10^{-4} \mathrm{M}$ \\
\hline $\begin{array}{l}\text { KM for ATP in presence of } \\
(0.16 \mathrm{M} \text { ethanol }\end{array}$ & $9 \times 10^{-4} \mathrm{M}$ & $54 \times 10^{-4} \mathrm{M}$ \\
\hline $\begin{array}{l}\text { Ki for oleic acid in presence } \\
\text { of }(0 \cdot 16 \mathrm{M} \text { cthanol }\end{array}$ & $4 \times 10^{-5} \mathrm{M}$ & $11 \times 10^{-5} \mathrm{M}$ \\
\hline Optimum pH & $7 \cdot()$ & $7 \cdot()$ \\
\hline Optimum $\mathrm{Na}^{*}$ & $120 \mathrm{mM}$ & $120 \mathrm{mM}$ \\
\hline Optimum $\mathrm{K}^{+}$ & $20 \mathrm{mM}$ & $20 \mathrm{mM}$ \\
\hline
\end{tabular}

intestine was inhibited to a greater extent by oleic acid at different levels than the Mg-ATPase from the same source (Fig. 3). The inhibition of $\mathrm{Na}$ $\mathrm{K}$-ATPase by oleic acid was noncompetitive in type (Fig. 4), whereas the inhibition of Mg-ATPase was uncompetitive (Fig. 5).

\section{Discussion}

The percentage distribution of the major fatty acids in faeces in control subjects and in patients with

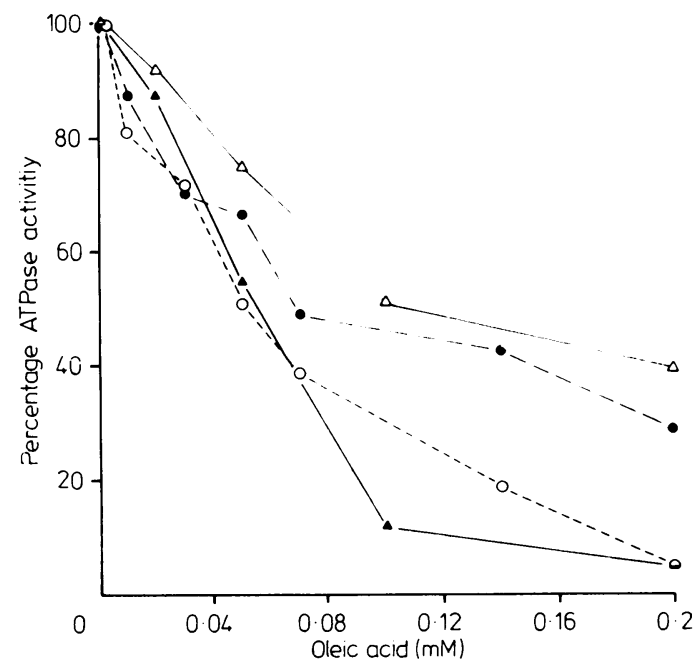

Fig. 3 Concentration dependent inhibition of rat enterocyte and colonocyte ATPases by oleic acid. Percentage activity was determined from control incubations without oleic acid. Values are expressed as the average of three different experiments with duplicates. ○-.--O enterocyte $\mathrm{Na} \mathrm{K}$-ATPase, $\bullet-.-\bullet$ enterocyte $\mathrm{Mg}$ ATPase, $\triangle \longrightarrow$ colonocyte Na K-ATPase, $\triangle \longrightarrow \triangle$ colonocyte Mg-ATPase.

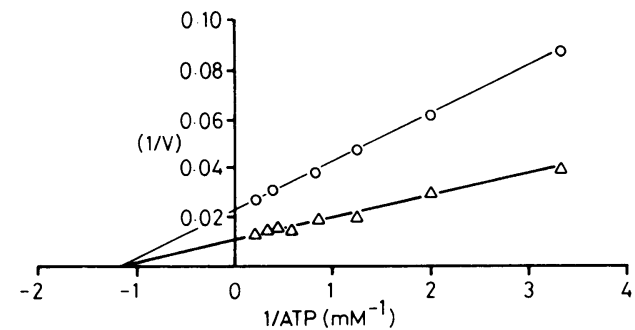

Fig. 4 Noncompetitive inhibition of enterocyte $\mathrm{Na} \mathrm{K}$ ATPase by oleic acid, $\triangle-\triangle$ control, $\bigcirc-O$ in the presence of $0.05 \mathrm{mM}$ oleic acid. Ratio of 2.1 for $\mathrm{Mg}^{2+}$ to ATP was maintained in assay medium.

tropical sprue was similar to the composition of dietary fatty acids (Fig. 1). indicating that nonabsorption of dietary fat is the major factor contributing to faecal fat in both groups. Only a small proportion of the faecal fat in subjects without steatorrhoea in southern India is of endogenous origin, in contrast with reports from temperate regions. ${ }^{17}$ This difference may be related to the high prevalence of tropical enteropathy with decreased absorptive capacity of the small intestine for fat, xylose, and other nutrients. ${ }^{18}$ The presence of similar amounts in faeces of controls and patients of arachidonic acid, an uncommon dietary fat in southern India, is probably a reflection of the small endogenous loss.

In tropical sprue, as in postileal resection, ${ }^{19}$ hydroxy fatty acids do not appear to play a

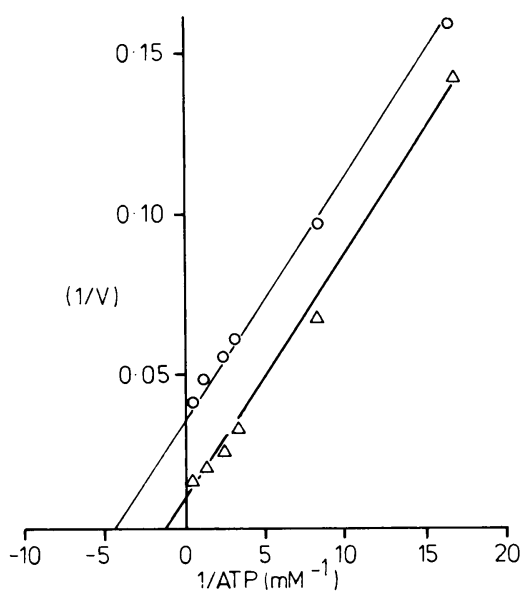

Fig. 5 Uncompetitive inhibition of colonocyte $M g$-ATPase by oleic acid. $\triangle \longrightarrow \triangle$ control. $\triangle \longrightarrow \circ$ in presence of 0.06 mM oleic acid. 
significant role in the pathogenesis of diarrhoea. The failure to detect hydroxystearic acid in half of the subjects is unlikely to be because of technical problems as the gas chromatographic method should detect hydroxy fatty acids at $1 \%$ of the total fatty acids, a level lower than in earlier reports. ${ }^{5}$ Although the two factors believed necessary for production of faecal hydroxystearate, sufficient amounts of free oleic acid and bacteria capable of hydrating the oleic acid to hydroxystearate ${ }^{20}$ were present, the absence of hydroxystearate in the faeces of several subjects suggests that other factors may be necessary for its production. These may be related to the nature of the dietary fat ${ }^{5}$ or the induction of the specific bacterial hydroxylases.

Faecal wet weight correlated well with total faecal fat and saturated and unsaturated fatty acids in the stool but not with hydroxy fatty acids. Intestinal perfusion studies showed that ricinoleic acid and oleic acid inhibit the absorption of water and solutes in the human intestine. ${ }^{2-24}$ Hydroxy fatty acids cause secretory diarrhoea by stimulation of adenylate cyclase ${ }^{25}$ while oleic acid does not stimulate this enzyme while producing watery diarrhoea. ${ }^{25}{ }^{26}$ It has been suggested that the effect of fatty acids may be related to decreased activity of the sodium pump. ${ }^{27} \mathrm{Na} \mathrm{K}$-ATPase is considered the biological counterpart of the sodium pump. maintaining the sodium gradient and electrical potential difference across cell membranes, although the exact role of this enzyme in sodium and water absorption is not yet fully understood. 2829 Significant reduction of water and electrolyte absorption was found when loops of small intestines were perfused in vivo with solutions containing ouabain, a potent inhibitor of Na K-ATPase. ${ }^{30}$ In children with active postenteritis syndrome, coeliac disease, and acute viral enteritis, a reduction in jejunal mucosal Na K-ATPase activity has been reported. ${ }^{31-33}$ The effect of oleic acid in perfusion studies was less than that of ricinoleic acid and recovered rapidly suggesting a reversible inhibition of an enzyme system. ${ }^{2.3}$

Fatty acids are known to inhibit a variety of enzymes. ${ }^{16} 34-36$ The results reported here extends the range of enzymes inhibited by fatty acids to include Na K-ATPase of the basolateral membranes of enterocytes and colonocytes. Unsaturated fatty acids were more inhibitory compared with saturated or hydroxy fatty acids (Table 2). Blocking the free carboxyl group in oleic acid by methylation reduced. but did not totally remove, its inhibitory effect. $\mathrm{Mg}$-ATPase of the basolateral membranes was also inhibited although to a lesser degree. This confirms earlier observations from this laboratory of fatty acid inhibition of enterocyte brush border $\mathrm{Mg}$ -
ATPase (unpublished observation), an enzyme thought to have a role in the maintenance of the mucosal acid microclimate. ${ }^{37}$ The mechanism of $\mathrm{Na}$ K-ATPase inhibition by fatty acids was noncompetitive and is possibly brought about by changes in membrane characteristics.

Although fatty acids are known to reduce water and electrolyte absorption in the human jejunum, ${ }^{21-2.3}$ it is possible that in tropical sprue jejunal contents are not in contact with the enterocyte for a sufficient period of time to produce an effect. Small intestinal in vivo perfusion studies in patients with tropical sprue in southern India have not shown water malabsorption sufficient to explain the severity of the diarrhoea ${ }^{38}$ and out of keeping with the enterocyte damage, characteristic of the disease. ${ }^{39}$ Colonic contents are, however, in intimate contact with the colonic epithelium for longer periods of time and their level is further increased by absorption of water, the normal physiological role of the colon. In patients with tropical sprue, a defect in colonic sodium and water absorption ${ }^{1}$ is accompanied by increased amounts of faecal unsaturated fatty acids, especially oleic acid. The results of these in vitro studies, correlation between faecal wet weight and faecal fatty acids, and the ability of unsaturated fatty acids to inhibit the colonocyte basolateral membrane ATPases, suggest one possible explanation for the pathogenesis of the colonic functional abnormality in tropical sprue. The extrapolation of in vitro results to the clinical situation, however, has to be made with caution especially since the abnormality of water and electrolyte absorption was shown in a situation where fatty acids were not present in the perfusion fluid.

The Wellcome Research Unit is supported by the Wellcome Trust, London.

\section{References}

1 Ramakrishna BS, Mathan VI. Water and electrolyte absorption by the colon in tropical sprue. Gut 1982; 23: 843-6.

2 Binder HJ. Fecal fatty acids - mediators of diarrhoea? Gastroenterology 1973; 65: 847-50.

3 Soong CS, Thompson JB, Poley JR, Hess DR. Hydroxy fatty acids in human diarrhoea. Gastroenterology 1972; 63: 748-57.

4 Ammon HV, Phillips SF. Inhibition of colonic water and electrolyte absorption by fatty acids in man. Gastroenterology 1973; 65: 744-9. 
5 Wiggins HS, Pearson JR, Walker J(j, Russell RI, Kellock TD. Incidence and significance of faceal hydroxystearic acid in alimentary disease. (jut 1974: 15: 614-21.

6 Baker SJ, Jacob R. Mathan VI. An evaluation of the $5 \mathrm{~g}$ D-xylose absorption test, with fractional urine collections, in subjects living in southern India. Int $J$ Med Res 1971: 59: 1869-77.

7 Van de Kamer JH. Huinink H. Ten Bokkal. Weyers HA. Rapid method for determination of fat in feces. $J$ Biol Chem 1949; 177: 347-55.

8 Cohen M, Morgan RGH. Hofman AK. One-step quantitative extraction of medium chain and long-chain fatty acids from aqueous samples. J Lipid Res 1969: 10: 614-6.

9 Morrison WR. Smith LM. Preparation of fatty acid methyl esters and dimethyl acetals from lipids with Boron Fluoride-Methanol. J Lipid Res 1964; 5: 60)(1-8.

10 Kim YW, Spritz N. Metabolism of hydroxy fatty acids in dogs with steatorrhoea secondary to experimentally produced intestinal blind loops. J Lipid Res 1968; 9: 487-91.

11 Matthys F, Christophe A, Verdonk G. A combined thin layer-gas chromatographic method for the analysis of fatty acid-containing stool fractions. Clin Chim Acta 1972; 36: 341-50.

12 Carroll KK. Quantitative estimation of peak areas in gas-liquid chromatography. Nature 1961: 191: 377-8.

13 Quigley JP. Gotterer SG. Distribution of $\left(\mathrm{Na}^{*}, \mathrm{~K}^{+}\right)$stimulated ATPase activity in rat intestinal mucosa. Biochim Biophys Acta 1969; 173: 456-68.

14 Lowry OH, Rosebrough NJ, Farr AL. Randall RJ. Protein measurement with the folin phenol reagent. $J$ Biol Chem 1951; 63: 495-518.

15 Taussky HH, Shorr EJ. A microcolorimetric method for the determination of inorganic phosphorus. $J$ Biol Chem 1953; 202: 675-85.

16 Ahmed K. Thomas BS. The effects of long chain fatty acids on sodium plus potassium ion-stimulated adenosine triphosphatase of rat brain. J Biol Chem 1971; 246: 103-9.

17 Webb JPW, James AT, Kellock TD. The influence of diet on the quality of faecal fat in patients with and without steatorrhoea. Gut 1963; 4: 37-41.

18 Baker SJ. Mathan VI. Tropical enteropathy and tropical sprue. Am J Clin Nutr 1972; 25: 1047-55.

19 Wiggins HS, Cummings JH, Pearson JR. Hydroxystearic acid and diarrhoea following ileal resection. Gut 1974; 15: 392-5.

20 Thomas PJ. Identification of some enteric bacteria which convert oleic acid to hydroxystearic acid in vitro. Gastroenterology 1972; 62: 430-5.

21 Ammon HV. Thomas PJ. Phillips SF. Effects of oleic and ricinoleic acids on net jejunal water and electrolyte movement. Perfusion studies in man. J Clin Invest 1974: 53: 374-9.

22 Ammon HV, Phillips SF. Inhibition of ileal water absorption by intraluminal fatty acids. Influence of chain length. hydroxylation and conjugation of fatty acids. J Clin Invest 1974; 53: 205-10.
23 Ammon HV, Thomas PJ. Phillips SF. Effects of long chain fatty acids on solute absorption: perfusion studies in the human jejunum. (jut 1977; 18: 805-13.

24 Ammon HV, Phillips SF. Inhibition of colonic water and electrolyte absorption by fatty acids in man. (iastroenterology 1973; 65: 744-9

25 Coyne MJ, Bonoris GG, Chung A, Conley D. Schoenfield LJ. Propranolol inhibits bile acid and fatty acid stimulation of cyclic AMP in human colon. Gastroenterology 1977; 73: 971-4.

26 Gaginella TS, Phillips SF, Dozois RR, (jo) VLW Stimulation of adenylate cyclase in homogenates of isolated intestinal epithelial cells from hamsters. Gastroenterology 1978: 74: 11-15

27 Gaginella TS, Phillips SF. Ricinoleic acid: current view of an ancient oil. Am J Dig Dis 1975; 20: 1171-7.

28 Skou JC. Enzymatic basis for active transport of $\mathrm{Na}^{+}$ and $\mathrm{K}^{+}$across cell membrane. Physiol Rev 1965: 45: 596-617.

29 Schultz SG, Curran PF. Sodium and chloride transport across isolated rabbit ileum. Curr Top Membr Transp 1974; 5: 225-81.

30) Charney AN, Donowitz M. Functional significance of intestinal $\mathrm{Na}^{+}-\mathrm{K}^{+}$-ATPase: in vivo ouabain inhibition. Am J Physiol 1978; 234: E629-36.

31 Tripp JH, Muller PRD, Harris JT. Mucosal ( $\left.\mathrm{Na}^{\circ}-\mathrm{K}^{\prime}\right)$ ATPase and adenylate cyclase activities in children with toddler diarrhea and postenteritis syndrome. Pediatr Res 1980: 14: 1382-6.

32 Tripp JH, Manning JA, Muller DRP et al. Mucosal adenylate cyclase and sodium potassium stimulated adenosine triphosphatase in jejunal biopsies of adults and children with coeliac disease. In: McNicholl B. McCarthy CF. Fottrell PF. eds. Perspectives in coeliac disease. Lancaster: MTP Press, 1978: 461-9.

33 McClung HJ, Butler DG. Kerzner B, Gall DG. Hamilton JR. Transmissible gastroenteritis: mucosal ion transport in acute viral enteritis. Gastroenterology 1976: 70: 1091-5

34 Miller HM. Woodhouse SP. Long chain fatty acid inhibition of sodium plus potassium activated adenosine triphosphatase from rat heart. Aust J Exp Biol Med Sci 1977; 55: 741-52.

35 Furuyama S. Doi N. Sugiya H, Mitsuma M. Effects of fatty acids on calcium stimulated adenosine triphosphatase in rat submandibular gland microsomes. Life Sci 1976; 19: 605-9.

36 Ramadoss CS. Wyeda K. Johnston JM. Studies on the fatty acid inactivation of phosphofructokinase. $J$ Biol Chem 1976; 251: 98-107.

37 Kesavan V. Noronha JM. An ATPase dependent radiosensitivie acidic microclimate essential for intestinal folate absorption. $J$ Phvsiol 1978; 280: 1-8.

38 Hellier MD, Radhakrishnan AN, Ganapathy V, Mathan VI. Baker SJ. Intestinal perfusion studies in tropical sprue. Gut 1976: 17: 511-6.

39 Mathan M, Mathan VI. Baker SJ. An electronmicroscopic study of jejunal mucosal morphology in control subjects and in patients with tropical sprue in southern India. Gastroenterology 1975; 68: 17-32. 